\title{
Article
}

\section{Proper Selection Does Make the Difference: A Propensity-Matched Analysis of Percutaneous and Surgical Cut-Down Transfemoral TAVR}

\author{
Marco Gennari ${ }^{1, *(\mathbb{D}}$, Marta Rigoni ${ }^{2,3}$, Giorgio Mastroiacovo ${ }^{1}{ }^{1}$, Piero Trabattoni ${ }^{1}$, Maurizio Roberto ${ }^{1}$, \\ Antonio L. Bartorelli ${ }^{4}$, Franco Fabbiocchi ${ }^{5}$, Gloria Tamborini ${ }^{6}{ }^{(D}$, Manuela Muratori ${ }^{6}$, Laura Fusini ${ }^{6}{ }^{\circ}$, \\ Mauro Pepi ${ }^{7}$, , Paola Muti ${ }^{3,8}$, Gianluca Polvani ${ }^{8,9}$ and Marco Agrifoglio ${ }^{1,8}$
}

1 Department of Cardiovascular Surgery, IRCCS Centro Cardiologico Monzino, 20100 Milan, Italy; gio.mastroiacovo@hotmail.it (G.M.); piero.trabattoni@ccfm.it (P.T.); maurizio.roberto@ccfm.it (M.R.); marco.agrifoglio@ccfm.it (M.A.)

2 Department of Industrial Engineering, University of Trento, 38100 Trento, Italy; marta.rigoni@unitnt.it

3 Department of Oncology and Health, Evidence, and Impact, McMaster University,

Hamilton, ON L8S 4L8, Canada; Paola.Muti@unimi.it

4 Department of Biomedical and Clinical Sciences "Luigi Sacco", University of Milan, 20100 Milan, Italy; antonio.bartorelli@ccfm.it

5 Department of Invasive Cardiology, IRCCS Centro Cardiologico Monzino, 20100 Milan, Italy; franco.fabbiocchi@ccfm.it

check for

updates

Citation: Gennari, M.; Rigoni, M.; Mastroiacovo, G.; Trabattoni, P.;

Roberto, M.; Bartorelli, A.L.;

Fabbiocchi, F.; Tamborini, G.;

Muratori, M.; Fusini, L.; et al. Proper

Selection Does Make the Difference:

A Propensity-Matched Analysis of

Percutaneous and Surgical Cut-Down

Transfemoral TAVR. J. Clin. Med.

2021, 10, 909. https://doi.org/

$10.3390 /$ jcm10050909

Academic Editor: Maurizio Taramasso

Received: 22 December 2020

Accepted: 18 February 2021

Published: 25 February 2021

Publisher's Note: MDPI stays neutral with regard to jurisdictional claims in published maps and institutional affiliations.

Copyright: (C) 2021 by the authors Licensee MDPI, Basel, Switzerland. This article is an open access article distributed under the terms and conditions of the Creative Commons Attribution (CC BY) license (https:// creativecommons.org/licenses/by/ $4.0 /)$.
6 Department of Cardiovascular Imaging, IRCCS Centro Cardiologico Monzino, 20100 Milan, Italy; gloria.tamborini@ccfm.it (G.T.); manuela.muratori@ccfm.it (M.M.); laura.fusini@ccfm.it (L.F.)

7 Clinical Area Director, IRCCS Centro Cardiologico Monzino, 20100 Milan, Italy; mauro.pepi@ccfm.it

8 Department of Biomedical, Surgical and Dental Sciences, University of Milan, 20100 Milan, Italy; gianluca.polvani@ccfm.it

9 Chief of Cardiovascular Surgery Department, IRCCS Centro Cardiologico Monzino, 20100 Milan, Italy

* Correspondence: marcogennari.md@gmail.com; Tel.: +39-02-58-0022-96

\begin{abstract}
Background. Transcatheter aortic valve replacement (TAVR) is an established technique to treat severe symptomatic aortic stenosis patients with a wide range of surgical risk. Currently, the common femoral artery is the first choice as the main access route for the procedure. The objective of this observational study is to report our experience on percutaneous and surgical cut-down transfemoral TAVRs comparing the two approaches. Methods. From January 2014 to January 2019, five hundred eleven consecutive patients underwent TAVR for severe symptomatic aortic stenosis. We analyzed only elective transfemoral procedures. After propensity score-matching based on age, sex, EuroSCORE II, mean aortic gradient, and left ventricular ejection fraction, we obtained two homogeneous populations: surgical cut-down $(n=119)$ and percutaneous $(n=225)$, which were labeled Group 1 and Group 2, respectively. Results. The main findings were that there were no significant procedural outcome differences between the two groups, but Group 2 patients had a shorter length of hospital stay and were more frequently discharged home. At follow-up, Group 1 patients had lower survival rates. Conclusions. An accurate preoperative assessment of the femoral access is mandatory to achieve satisfactory outcomes with transfemoral TAVRs. Nevertheless, the percutaneous approach allows shorter in-hospital stay and the need for rehabilitation, thus potentially decreasing the costs of the procedure.
\end{abstract}

Keywords: TAVR; percutaneous access; vascular complications; surgical cut-down; transfemoral approach

\section{Background}

Transcatheter aortic valve replacement (TAVR) is an established procedure to treat patients with severe symptomatic aortic stenosis (AS) at high and intermediate surgical risk. After PARTNER 3 and Evolut R low-risk trials [1,2] showing non-inferiority to surgical aortic valve replacement (SAVR) of the latest generation balloon-expandable 
and self-expanding valves, it is expected for there to be an increase of the number of transcatheter-based replacements of the aortic valve.

Currently, the transfemoral route is the preferred main access for the procedure [3] gained by either surgical cut-down or the percutaneous approach (Figure 1), the latter being the first choice whenever feasible. Despite the lower profile of the delivery catheters of the latest generation of transcatheter aortic valves (TAVs) and that the improvements of the performance of large-bore vascular closure devices (VCDs) had turned into an overall reduction in bleedings or major vascular complications, troubles at the vascular access site still have an impact on the outcome [4].

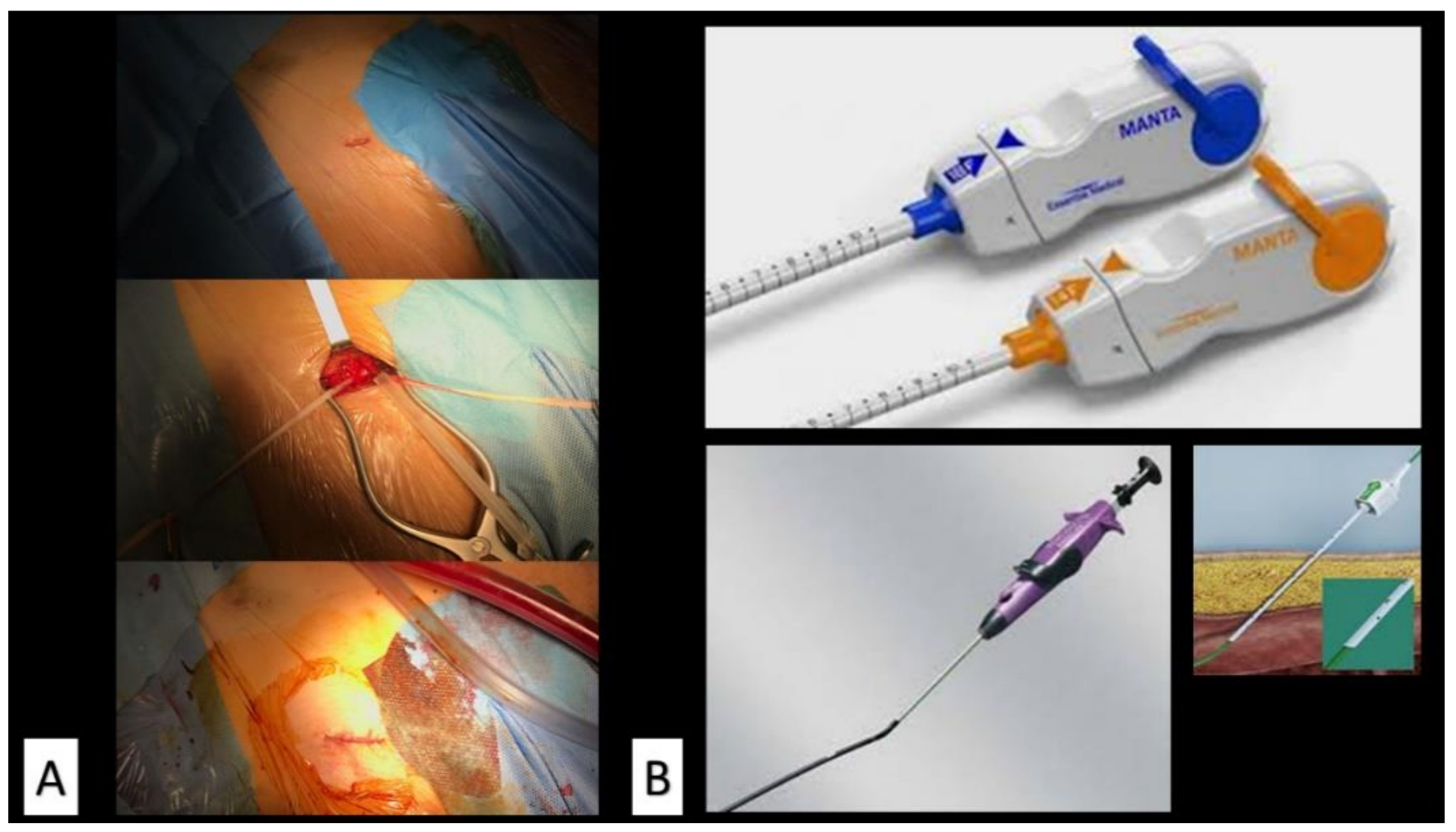

Figure 1. (A) Minimal surgical incision at the groin for the isolation of the common femoral artery. (B) Currently the most widely used vascular closure devices for large-bore arterial holes.

Surgical cut-down of the common femoral artery may allow better control and repair in case of complications, but it is burdened by all the classical surgical access-related problems [5] such as invasiveness, longer recovery, infection risk, lymphatic or neurological issues, and currently, a fully percutaneous approach with VCDs use is the preferred choice [6].

The aim of this observational study is to report our experience, outcomes, and followup of the transfemoral TAVRs with the currently available devices performed by either a surgical cut-down or a percutaneous approach.

\section{Methods}

This is an observational study of the perioperative and follow-up outcomes of both surgical cut-down and percutaneous transfemoral TAVRs, compared by a propensity score-matching of the two populations. Figure 2 depicts the patients' selection process flow chart. 


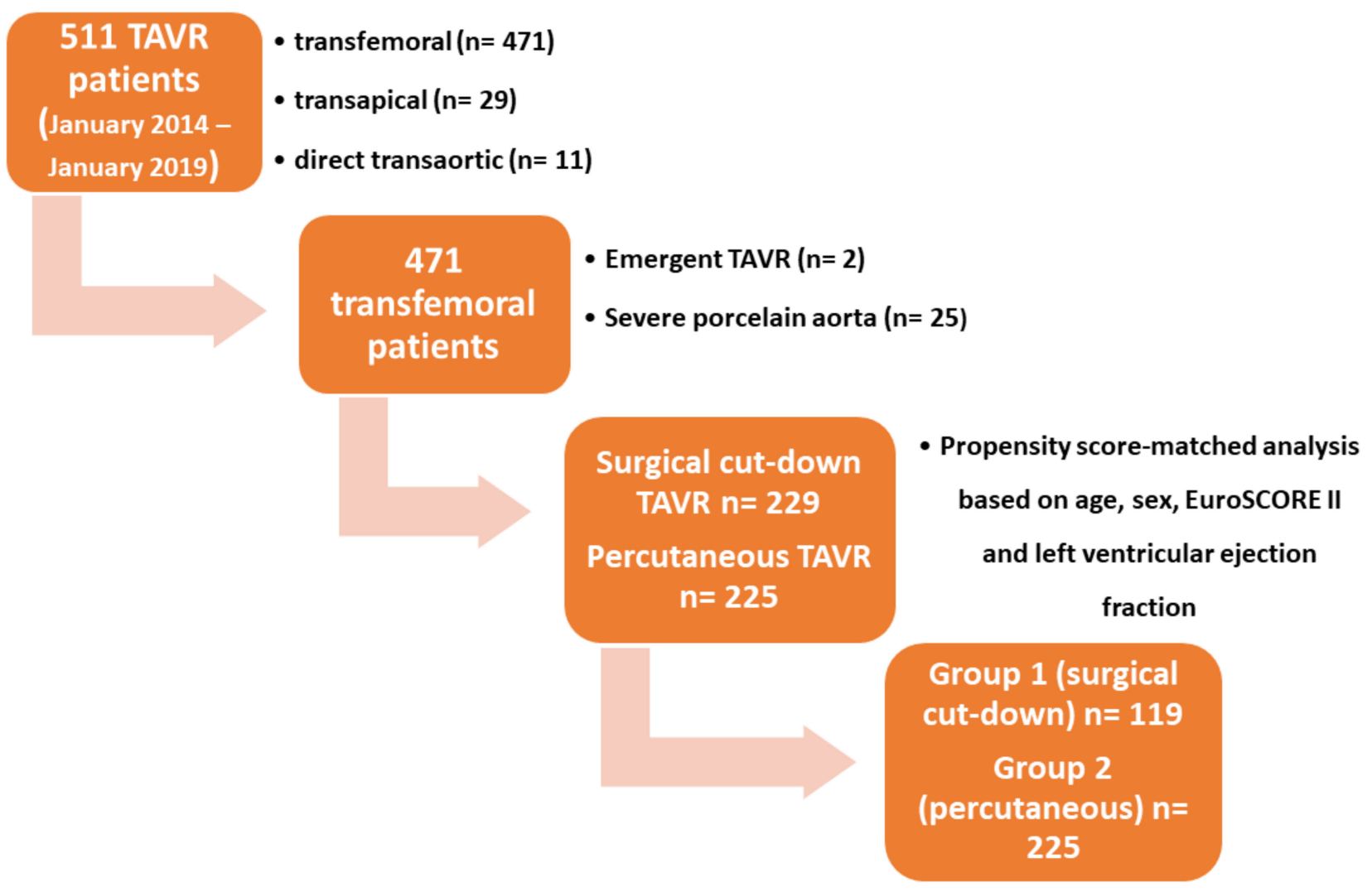

Figure 2. Flow chart of the study. Legend. TAVR = trancatheter aortic valve replacement.

\subsection{Patients}

From January 2014 to January 2019, five hundred-eleven patients with severe symptomatic aortic stenosis were treated at our institution with both transfemoral balloonexpandable and self-expanding TAVR by the same surgical group. The decision to perform the transcatheter procedure was made by the local Heart Team according to established criteria [7]. The routes of delivery of the transcatheter heart valves (THVs) were femoral $(n=471)$, left ventricular apex $(n=29)$, and direct aortic $(n=11)$. Only elective transfemoral TAVRs have been analyzed in this work. Emergency procedures $(n=2)$ and patients with challenging porcelain aorta $(n=25)$ were excluded from the analysis.

We divided the remaining 444 patients into two groups-according to the surgical $(n=219)$ or percutaneous access $(n=225)$ to the femoral artery. Since these raw populations presented a relevant mismatch of the baseline characteristics (Table 1), we performed a propensity score-matched analysis based on age, sex, EuroSCORE II, body mass index (BMI), hypertension, diabetes, mean aortic gradient, and left ventricular rejection fraction, obtaining two homogeneous populations of 119 and 225 patients for the surgical and percutaneous group that we labeled Group 1 and Group 2, respectively. The majority of the patients were at intermediate surgical risk (Group 1 presenting a median EuroSCORE II of 4.09 and Group 2 presenting a score 3.77). The frailty burden was considered comparable for both populations after Heart Team evaluation. The decision to perform a surgical or a percutaneous approach was made in the Heart Team context after careful analysis of a contrast-enhanced non-electrocardiogram-guided multi-slice computed tomography (MSCT) of the abdominal aorta and femoral vessels. Briefly, in case of moderate, non-anterior wall calcifications and in the presence of adequate arterial diameters, the percutaneous approach was preferred. In case of borderline diameter with a sheath-tofemoral artery ratio (STFR) $>1.05$ [8] or severe concentric calcifications and tortuosity, a direct surgical cut-down of the vessel was favored. Anyway, a final decision on the type of the femoral access was left to the discretion of the operator. 
Table 1. Baseline characteristics of the unmatched groups (surgical cut-down versus percutaneous) transcatheter aortic valve replacement (TAVR).

\begin{tabular}{cccc}
\hline & \multicolumn{3}{c}{ Unmatched } \\
\hline Variables & Surgical Cut-Down & Percutaneous & $p$-Value \\
\hline Total Population $(n)$ & 219 & 225 & \\
\hline Age, Median (q1-q3) & $81(77-85)$ & $83(79-86)$ & $<0.01$ \\
\hline Male, $n(\%)$ & $105(47.9)$ & $130(57.8)$ & 0.04 \\
\hline Female, $n(\%)$ & $114(52.1)$ & $95(42.2)$ & \\
\hline BMI, Median (q1-q3), kg/m ${ }^{2}$ & $25.1(22.2-28.7)$ & $25.1(23.4-28.0)$ & 0.37 \\
\hline Hypertension, $n(\%)$ & $166(76.2)$ & $180(80.0)$ & 0.36 \\
\hline Diabetes, $n(\%)$ & $55(25.2)$ & $52(23.1)$ & 0.66 \\
\hline COPD & $13(6)$ & $11(5)$ & 0.33 \\
\hline Peripheral Vascular Disease, $n(\%)$ & $82(37.6)$ & $55(24.4)$ & $<0.01$ \\
\hline Creatinin, Median (q1-q3), mg/dL & $1.00(0.81-1.26)$ & $1.02(0.81-1.29)$ & 0.35 \\
\hline Hb, Mean (SD), (g/dL) & $12.4(1.7)$ & $3.67(1.6)$ & 0.34 \\
\hline EuroSCORE II log, Median (q1-q3) & $4.13(2.52-6.75)$ & $34(15.3)$ & 0.21 \\
\hline Atrial Fibrillation, $n(\%)$ & $36(16.7)$ & $43(35-52)$ & 0.70 \\
\hline Mean Aortic Gradient, Median & $46(39-55)$ & $59(50-66)$ & 0.02 \\
\hline (q1-q3), mmHg & $61(53-67)$ & $35(31-42)$ & 0.22 \\
\hline EF, Median (q1-q3) & $35(31-42)$ & & \\
\hline PAPs, median (q1-q3), mmHg & & & \\
\hline
\end{tabular}

Legend: $\mathrm{BMI}=$ body mass index $; \mathrm{COPD}=$ chronic obstructive pulmonary disease; $\mathrm{Hb}=$ hemoglobin; $\mathrm{EF}=$ ejection fraction; PAPs = pulmonary artery pressures; $\mathrm{q} 1$ = first quartile; $\mathrm{q} 3$ = third quartile.

\subsection{Ethical Committee}

This work is based on a retrospective review of data prospectively collected with follow-up information retrieved by telephone calls and hospital records. This research has been approved by the Institutional Review Board (IRB), in accordance with the principles of the Declaration of Helsinki. The local ethical committee waived the requirement for individual consent for the study due to the retrospective nature of our analysis.

\subsection{Surgical Cut-Down Technique}

A 3-cm long transversal incision is made $\approx 1 \mathrm{~cm}$ above the inguinal fold. After that, the subcutaneous tissue is longitudinally dissected, and the common femoral artery is approached laterally to decrease the hazard of lymphatic injury. Once the proximal and distal segments of the artery are encircled with a vascular lace, the anterior wall is manually palpated to find the best area for the access. Hereby, a non-calcific area is chosen, a double ( $180^{\circ}$ degrees apart) $5-0$ purse-string proline stitch is placed, and a tourniquet snaring system is applied. Afterwards, the artery is directly punctured under vision and tactile feedback. At the end of the procedure, the sutures are tight and the pulse is evaluated; if a relevant stenosis is suspected, the artery is temporary clamped, the purse-string sutures are removed, and the arterial wall is repaired.

\subsection{Percutaneous Access Technique}

For all the percutaneous procedures, we utilize the double pre-closing technique with two 6Fr Proglide (Abbott, Chicago, IL, USA) deployed at the 10 and 2 o'clock positions. After removing the procedural sheath and tightening the sutures, a bleeding check is performed; if satisfactory hemostasis is achieved, the sutures are further bounded and then cut. If bleeding is still an issue, manual compression or contralateral crossover management 
is performed (with peripheral balloon occlusion and stent-graft placement when indicated). A similar management is adopted in case of significant femoral stenosis.

\subsection{Outcomes and Follow-Up}

Most of the patients were followed up in our outpatient clinic, and the follow-up was completed in $100 \%$ of them. About $85 \%$ were clinical follow-ups, while the remaining were made by phone calls. The outcomes analyzed were procedural results according to VARC-2 (Valve Academic Research Consortium-2) definitions [9], median length of hospital stay, discharge destination, mortality at follow-up, New York Heart Association (NYHA) class, and rehospitalizations. Major adverse cardiovascular and cerebrovascular events (MACCE) as well as survival data were collected.

\subsection{Statistical Analysis}

Descriptive variables were expressed by mean \pm standard deviation (SD) in case of normal distribution, or by median and first and third quartiles (q1, q3 respectively) in case of non-normal distribution. The normality of the variables was tested with the Shapiro-Wilk test. The dichotomous variables or scores were expressed as frequencies and occurrence percentages.

Variables and outcomes were compared between the two groups using the most appropriate test according to the type and nature of the data among the $t$-test for independent samples, nonparametric Mann-Whitney U-test, Pearson's chi-squared test, or Fisher's exact test.

The Cox proportional hazard model was used to estimate the hazard ratio (HR) and $95 \%$ confidence Interval (95\% CI) for all-cause mortality for the percutaneous group in respect to the surgical cut-down group. Moreover, Kaplan-Meier estimates analysis was used to generate a time-to-event curve for all-cause mortality, and all event mortality was stratified by access type (surgical cut-down or percutaneous).

All tests were 2-tailed, and a $p$-value $<0.05$ was set for statistical significance.

Statistical analyses were performed using the Stata software (StataCorp LLC 1996-2021, 4905 Lakeway Drive, College Station, TX, USA).

\section{Results}

\subsection{Baseline Characteristics}

The baseline characteristics of the two matched groups are listed in Table 2. After the propensity-score matching, only the body mass index (BMI) differed between the two populations, being higher in Group $2(p=0.05)$. No differences were found in the incidence of previous coronary interventions (Table 3), either coronary artery bypass or percutaneous coronary interventions, while Group 1 presented a higher incidence of previous surgical aortic valve replacements (SAVRs) $(n=8, p<0.01)$. 
Table 2. Baseline characteristics of the matched groups (surgical cut-down versus percutaneous) TAVR.

\begin{tabular}{|c|c|c|c|}
\hline \multirow[b]{2}{*}{ Variables } & \multicolumn{3}{|c|}{ Unmatched } \\
\hline & $\begin{array}{c}\text { Group } 1 \\
\text { Surgical Cut-Down }\end{array}$ & $\begin{array}{c}\text { Group } 2 \\
\text { Percutaneous }\end{array}$ & $p$-Value \\
\hline Total Population $(n)$ & 119 & 225 & \\
\hline Age, Median (q1-q3) & $83(78-85)$ & $83(79-86)$ & 0.45 \\
\hline Male, $n(\%)$ & $67(56.3)$ & $130(57.8)$ & 0.79 \\
\hline Female, $n(\%)$ & $52(43.7)$ & $95(42.2)$ & \\
\hline BMI, Median (q1-q3), kg/m2 & $24.7(22.3-27.5)$ & $25.1(23.4-28.0)$ & 0.05 \\
\hline Hypertension, $n(\%)$ & $89(74.8)$ & $180(80.0)$ & 0.27 \\
\hline Diabetes, $n(\%)$ & $27(22.7)$ & $52(23.1)$ & 0.93 \\
\hline COPD & $7(6)$ & $11(5)$ & 0.21 \\
\hline Peripheral Vascular Disease, $n(\%)$ & $37(31.1)$ & $55(24.4)$ & 0.19 \\
\hline Creatinin, Median (q1-q3), mg/dL & $1.00(0.82-1.32)$ & $1.02(0.81-1.29)$ & 0.81 \\
\hline $\mathrm{Hb}$, Mean (SD), (g/dL) & $12.5(1.6)$ & $12.6(1.6)$ & 0.57 \\
\hline EuroSCORE II log, Median (q1-q3) & $4.09(2.61-7.29)$ & $3.77(2.33-5.22)$ & 0.22 \\
\hline Atrial Fibrillation, $n(\%)$ & $22(18.6)$ & $34(15.3)$ & 0.44 \\
\hline $\begin{array}{l}\text { Mean Aortic Gradient, Median } \\
\text { (q1-q3), mmHg }\end{array}$ & $45(38-54)$ & $43(35-52)$ & 0.30 \\
\hline EF, Median (q1-q3) & $61(48-67)$ & $59(50-66)$ & 0.35 \\
\hline PAPs, Median (q1-q3), mmHg & $35(31-42)$ & $35(31-42)$ & 0.37 \\
\hline
\end{tabular}

Legend: $\mathrm{BMI}=$ body mass index; $\mathrm{COPD}=$ chronic obstructive pulmonary disease; $\mathrm{Hb}=$ hemoglobin; $\mathrm{EF}=$ ejection fraction; PAPs = pulmonary artery pressures; $\mathrm{q} 1$ = first quartile; $\mathrm{q} 3$ = third quartile.

Table 3. Cardiovascular baseline characteristics of the matched populations.

\begin{tabular}{cccc}
\hline & \multicolumn{3}{c}{ Matched Populations } \\
\hline Variables & Group 1 & Group 2 & $p$-Value \\
\hline History of Coronaropathy, $n(\%)$ & $45(37.8)$ & $92(40.9)$ & 0.58 \\
\hline Previous CABG o PCI, $n(\%)$ & $19(16.0)$ & $50(22.2)$ & 0.17 \\
\hline Previous Cardiac Surgery (\%) & $31(26.1)$ & $39(17.3)$ & 0.07 \\
\hline Previous SAVR, $n(\%)$ & $8(7.0)$ & $0(0.0)$ & $<0.01$ \\
\hline $\begin{array}{c}\text { Severe Peripheral Vascular } \\
\text { Disease, } n(\%)\end{array}$ & $37(31.1)$ & $55(24.4)$ & 0.19 \\
\hline EF, Median (q1-q3) & $61(48-67)$ & $59(50-66)$ & 0.35 \\
\hline
\end{tabular}

Legend: $\mathrm{CABG}=$ coronary artery bypass grafting; $\mathrm{PCI}=$ percutaneous coronary interventions; $\mathrm{SAVR}=$ surgical aortic valve replacement; $\mathrm{EF}=$ ejection fraction.

All the procedures (except one) were performed in deep sedation and oro-tracheal intubation. We analyzed only third-generation devices (Sapien 3, Edwards Lifesciences, Irvine, USA and Evolut R, Medtronic, Minneapolis, USA). Most of the procedures were accomplished using the balloon-expandable platform. No differences between the two groups were recorded on the diameter of the TAVs (Table 4).

Similarly, we did not observe any statistical differences in the femoral sheath diameter (14Fr and 16Fr Edwards eSheath or 14Fr EnVeo R InLine Medtronic sheath). 


\subsection{In-Hospital Outcomes}

No relevant intraprocedural or periprocedural differences were found between the surgical and percutaneous groups in terms of MACCE, major bleedings, major vascular complications, or neurological complications according to VARC-2 criteria (Table 5).

Table 4. Procedural features of the matched populations.

\begin{tabular}{|c|c|c|c|}
\hline Variable & Group 1 & Group 2 & $p$-Value \\
\hline \multicolumn{4}{|l|}{ Type of Anesthesia } \\
\hline Deep Sedation, $n(\%)$ & $119(100.0)$ & $224(99.5)$ & \multirow[b]{2}{*}{1.0} \\
\hline $\begin{array}{l}\text { Local Anesthesia + Mild } \\
\text { Sedation, } n(\%)\end{array}$ & $0(0.0)$ & $1(0.5)$ & \\
\hline \multicolumn{4}{|l|}{ Type of TAV } \\
\hline Self-Expanding TAV, $n(\%)$ & $5(4.2)$ & $12(5.3)$ & \multirow{2}{*}{0.80} \\
\hline Balloon-Expandable TAV, $n(\%)$ & $114(95.8)$ & $213(94.7)$ & \\
\hline \multicolumn{4}{|l|}{ TAV's Diameter } \\
\hline $20 \mathrm{~mm}, n(\%)$ & $3(2.5)$ & $1(0.5)$ & \multirow{4}{*}{0.17} \\
\hline $23 \mathrm{~mm}, n(\%)$ & $52(43.7)$ & $87(38.7)$ & \\
\hline $26 \mathrm{~mm}, n(\%)$ & 47 (39.5) & $109(48.4)$ & \\
\hline $29 \mathrm{~mm}, n(\%)$ & $17(14.3)$ & $28(12.4)$ & \\
\hline \multicolumn{4}{|l|}{ Femoral Sheaths } \\
\hline 14F eSheath $n(\%)$ & $100(84)$ & $191(84.9)$ & \multirow{3}{*}{0.35} \\
\hline 14F EnVeo R InLine Sheath $n(\%)$ & $5(4.2)$ & $12(5.3)$ & \\
\hline 16 F eSheath $n(\%)$ & $14(11.8)$ & $22(9.8)$ & \\
\hline
\end{tabular}

Legend: $\mathrm{TAV}=$ transcatheter aortic valve.

\subsection{Clinical Outcome at Follow-Up}

The median follow-up for Group 1 was 949 days (interquartile range 624-1434) and for Group 2, it was 1039 days (interquartile range 703-1553, $p=0.27$ ). The main differences are listed in Table 6.

The percutaneous group had a significantly shorter length of hospital stay and was more frequently discharged home, while the surgical group frequently needed a postoperative rehabilitation. We generally offer postoperative rehabilitation to the surgical patients because we want to follow the correct healing of the surgical access, while the percutaneous patients are candidates to rehabilitation only in case of specific situations, such as post procedural rhythm disturbances.

Kaplan-Meier survival estimates (Figure 3) showed a survival rate higher for Group 2 , with a crude HR $=0.61 ; 95 \% \mathrm{CI}=0.40-0.94 ; p=0.03$. This means that in our analysis, the percutaneous approach was associated with a reduction in the morality hazard of $39 \%$ compared with the surgical counterpart. 
Table 5. Procedural results (Valve Academic Research Consortium-2 definitions) of the matched populations.

\begin{tabular}{cccc}
\hline Outcome & Group 1 & Group 2 & $p$-Value \\
\hline Intraprocedural Death, $n(\%)$ & $1(0.8)$ & $5(2.2)$ & 0.67 \\
\hline Cardiac Arrest, $n(\%)$ & $1(0.8)$ & $4(1.8)$ & 0.66 \\
\hline Cardiovascular Mortality, $n(\%)$ & $1(0.8)$ & $4(1.8)$ & 0.66 \\
\hline More than Mild PVL, $n(\%)$ & $7(6.0)$ & $19(8.7)$ & 0.09 \\
\hline Device Embolization, $n(\%)$ & $0(0)$ & $0(0)$ & 0.00 \\
\hline Need for CPB/ECMO, $n(\%)$ & $1(0.8)$ & $1(0.4)$ & 1.00 \\
\hline Conversion to Sternotomy, $n(\%)$ & $1(0.8)$ & $1(0.4)$ & 1.00 \\
\hline Device Success, $n(\%)$ & $116(98.3)$ & $219(97.3)$ & 0.72 \\
\hline Minor Vascular Complications, $n(\%)$ & $6(5.1)$ & $10(4.5)$ & 0.97 \\
\hline Major Vascular Complications, $n(\%)$ & $3(2.6)$ & $6(2.7)$ & 1.00 \\
\hline Coronary Occlusion, $n(\%)$ & $0(0)$ & $1(0.4)$ & 1.00 \\
\hline New Onset AF, $n(\%)$ & $6(5.1)$ & $13(5.8)$ & 0.79 \\
\hline AMI, $n(\%)$ & $1(0.8)$ & $0(0)$ & 0.34 \\
\hline Temporary Postoperative CVVH, $n(\%)$ & $1(0.8)$ & $2(0.9)$ & 0.48 \\
\hline Minor Neurological Events, $n(\%)$ & $1(0.85)$ & $5(2.2)$ & 0.38 \\
\hline Major Neurological Events, $n(\%)$ & $0(0.0)$ & $22(9.9)$ & 0.78 \\
\hline Major Bleedings, $n(\%)$ & $9(7.7)$ & $3(1.3)$ & 0.44 \\
\hline Minor Bleedings, $n(\%)$ & $3(2.6)$ & $12(5.4)$ & 0.28 \\
\hline PPI, $n(\%)$ & $3(5.6)$ & 1.00 \\
\hline PVI $)$ & $(0.9)$ & 0.00 \\
\hline
\end{tabular}

Legend: $\mathrm{PVL}$ = paravalvular leak; $\mathrm{CPB}$ = cardio-pulmonary bypass; ECMO = extracorporeal membrane oxygenation; $\mathrm{AF}=$ atrial fibrillation; $\mathrm{AMI}=$ acute myocardial infarction; $\mathrm{PPI}=$ permanent pacemaker implantation; $\mathrm{CVVH}=$ continuous veno-venous hemofiltration

Table 6. Outcomes and follow-up of the matched populations.

\begin{tabular}{cccc}
\hline Outcomes & Group 1 & Group 2 & $p$-Value \\
\hline $\begin{array}{c}\text { Length of Stay, Median (q1-q3), } \\
\text { days }\end{array}$ & $7(5-9)$ & $5(4-7)$ & $<0.01$ \\
\hline Discharged Home, $n(\%)$ & $18(15.5)$ & $194(88.2)$ & $<0.01$ \\
\hline Rehabilitation, $n(\%)$ & $98(84.5)$ & $26(11.8)$ & $<0.01$ \\
\hline Follow-Up Mortality, $n(\%)$ & $37(31.6)$ & $48(21.8)$ & 0.05 \\
\hline $\begin{array}{c}\text { Follow-Up Cardiovascular } \\
\text { Mortality al, } n(\%)\end{array}$ & $11(9.4)$ & $22(10.1)$ & 0.85 \\
\hline Median Follow-Up (q1-q3), Days & $949(624-1434)$ & $1039(703-1553)$ & 0.83 \\
\hline NYHA 1 at Follow-Up, $n(\%)$ & $94(83.9)$ & $184(86.4)$ & \\
\hline NYHA 2 at Follow-Up, $n(\%)$ & $16(14.3)$ & $26(12.2)$ & 0.22 \\
\hline NYHA 3 at Follow-Up, $n(\%)$ & $2(1.8)$ & $3(1.4)$ & $22(10.3)$ \\
\hline $\begin{array}{c}\text { Cardiovascular } \\
\text { Rehospitalization, } n(\%)\end{array}$ & $7(6.3)$ & & \\
\hline
\end{tabular}

Legend: NYHA = New York Heart Association; q1 = first quartile; q3 = third quartile. 


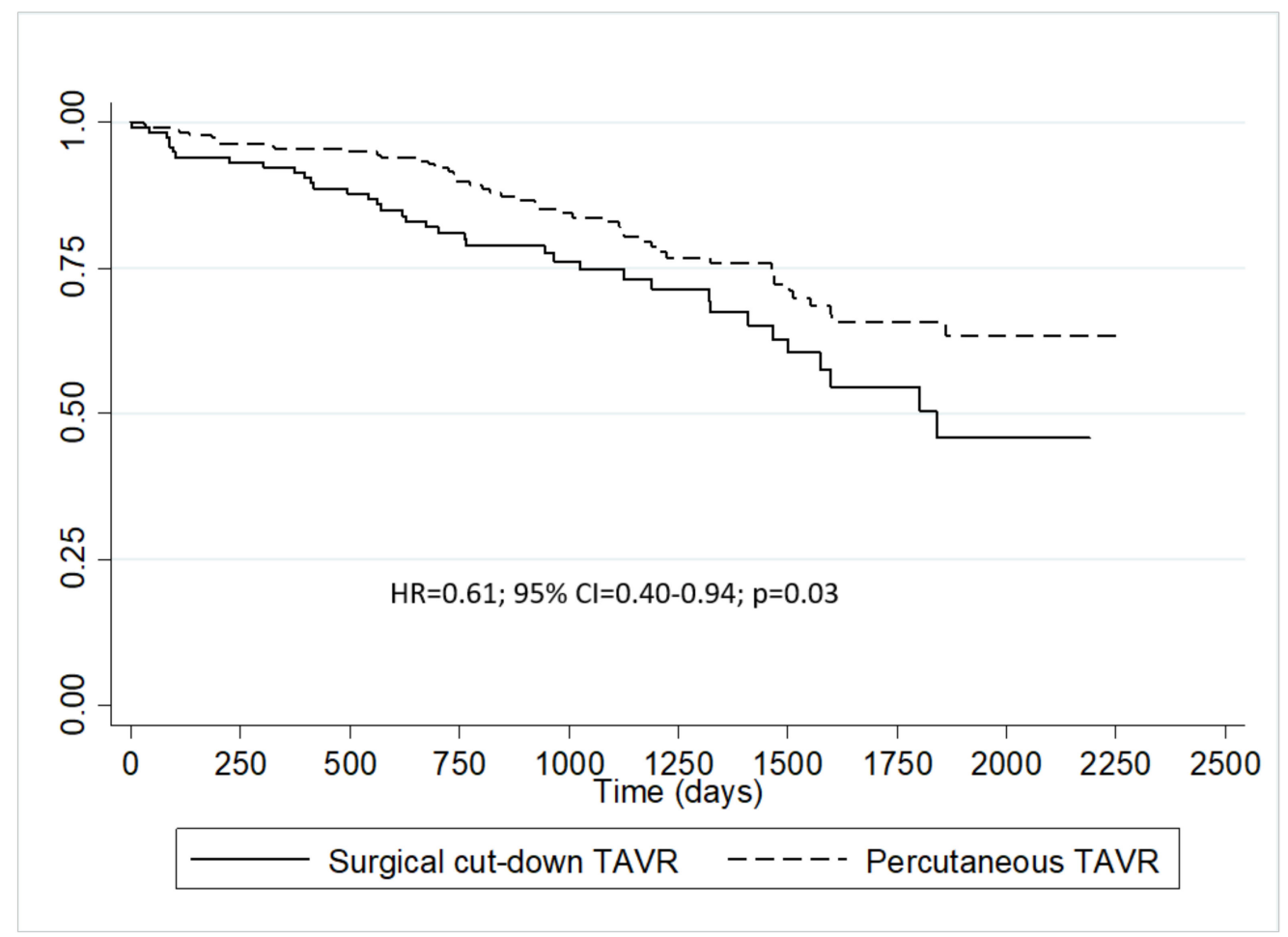

Figure 3. Kaplan-Meier survival estimates. Legend. $\mathrm{CI}=$ confidential interval; $\mathrm{HR}=$ hazard ratio; $\mathrm{TAVR}=$ transcatheter aortic valve replacement.

\section{Discussion}

The main findings of this report are as follows: (i) an accurate preoperative assessment of the femoral vasculature is mandatory to achieve a low rate of major access-related complications; (ii) even though the operative results were similar for the two groups, patients underwent percutaneous access had a significantly lower length of hospital stay and were more frequently discharged home, potentially reducing the overall costs of the procedure; (iii) and finally, the percutaneous group presented higher survival rates at follow-up.

The latest generation of TAVs are deployed with a lower profile regarding their delivery catheters compared to the early generation devices [10,11]; this has led to a progressive shift toward a less invasive totally percutaneous approach to the femoral artery [12]. Although technical and expertise improvements in the last years have yielded to better outcomes, the incidence of vascular complications after TAVR is still reported to be between $8 \%$ and $30 \%$ [12].

Whatever the way of access, vascular complications after TAVR are linked to an excess mortality.

Accurate pre-procedural planning of the access is crucial for a safe vascular outcome. The MSCT is currently the main stem of the pre-TAVR assessment [13]; in particular, minimum diameters of the ilio-femoral axes, calcifications burden, and degrees of tortuosity are well-established features that may affect the risk of vascular injury. Although a profile reduction of the delivery systems and an ultrasound-guided approach to the femoral vessels [14] can reduce the hazard of vascular troubles, the choice of the right way of access still play a role. We report our Heart Team experience depicting comparable operative outcomes of both surgical and percutaneous approach, given a deep pre-procedural assessment of the clinical and anatomical characteristics (Figure 4). 


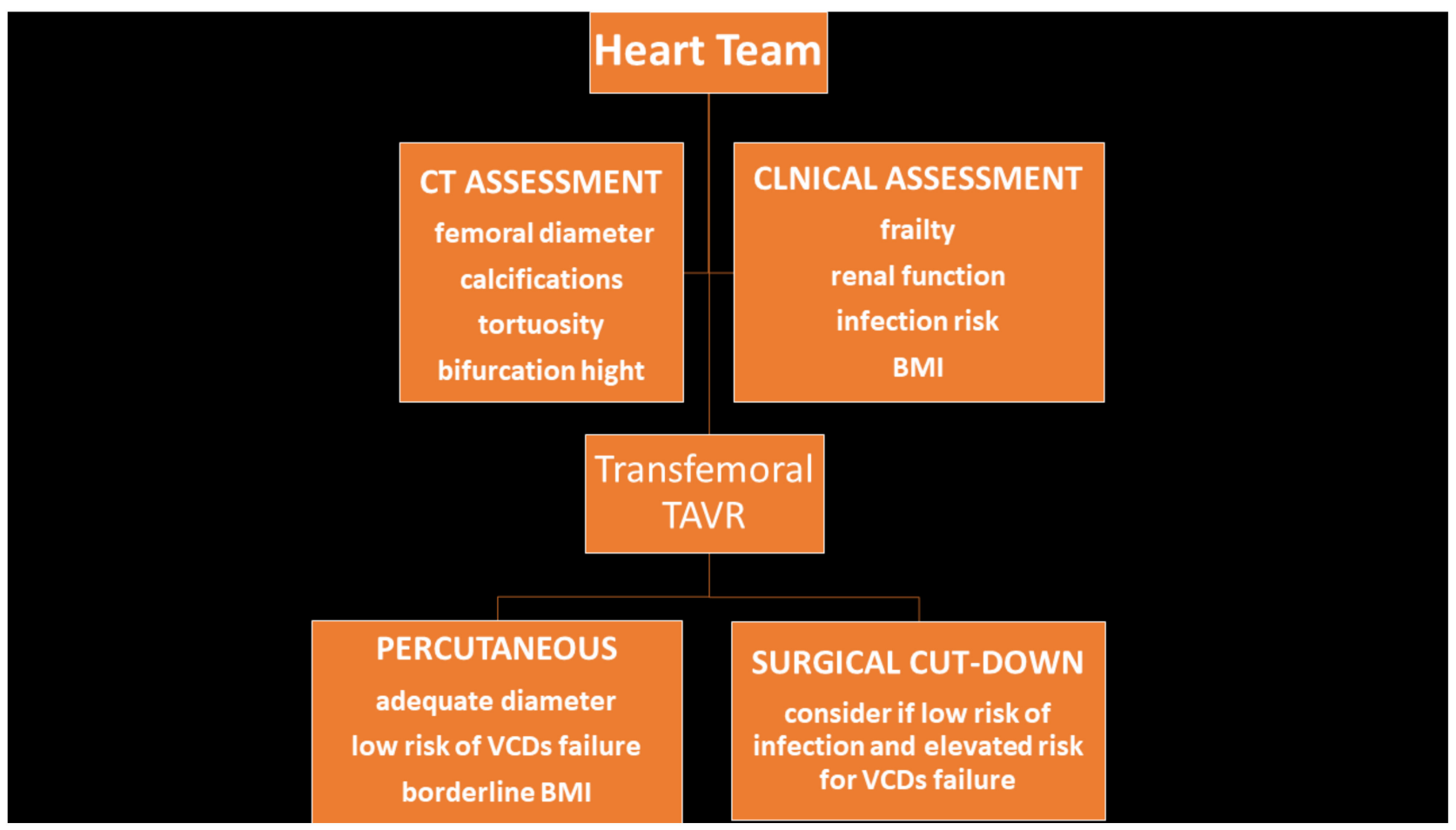

Figure 4. Flow chart of the decision-making to perform surgical cut-down versus percutaneous femoral access.

Despite the favorable results, the greater invasiveness of the surgical cut-down of the femoral artery has led to an overall prolonged in-hospital stay and the need for postoperative rehabilitation.

This may affect the outcome in two ways. The slower recovery of the surgical group may predispose to prolonged immobilization and increased infections rates [15,16], which are all known concerns in these frail surgical candidates. Indeed, lymphoceles and paresthesia complications are quite more common when a surgical femoral isolation is performed [17]. We do not insert an inguinal drain on a regular basis, but only in selected populations such as obese patients or if an extensive arterial dissection is performed; in these cases, the drain can help reduce the common local post-procedural complications (such as infections, lymphoceles) at the expense of a prolonged in-hospital stay.

Secondly, the prolonged hospitalization may affect the costs of the procedure [18], despite the intrinsic costs of the percutaneous toolbox including the vascular closure devices (VCDs).

Most of the available data on the outcome of surgical or percutaneous transfemoral TAVR are derived from registries, case series, and observational studies, whose results are in line with our report [19].

Only a small, randomized clinical trial [20] has prospectively evaluated the outcomes between the two groups, determining that high-volume experienced centers may perform a total percutaneous approach with a low rate of vascular problems.

Finally, we report a higher mortality rate for the surgical group. Although definitive conclusions could not be driven from this evidence, a possible explanation is that the surgical group could have presented a higher global atherosclerotic cardiovascular burden (witnessed by eight valve-in-valve procedures), determining an increased mortality at follow-up. In fact, we speculated that even though the matched baseline characteristics were similar between the two groups, the impact of the cardiovascular risk factors might have a more deep impact on patients who have previously undergone open-heart surgery. 


\section{Limitations}

This report is affected by several limitations. First, it is a single-center observational analysis. Secondly, the preoperative decision to perform a surgical or percutaneous approach may resent several inter-operator biases. Another limitation is related to our practice in the management of the discharge of the surgical or percutaneous transfemoral TAVR patient; as it is an internal routine and there is currently a lack of evidence-based guidelines, a final conclusion on the benefit of either the rehabilitation or home discharge can not be reached. Finally, most of the experience was along the balloon-expandable platform, making it hard to drive comparison with other platform sheaths.

\section{Conclusions}

The preoperative selection of the patients based on MSCT is mandatory to improve the vascular and general outcome of the TAVR procedures. The percutaneous approach in the selected population drives a fast in-hospital length of stay and home-based recovery. In our series, it is also linked to better survival rates. In the new parading of tailoring the management of the structural heart disease patient, we believe that handling both techniques (i.e., surgical and percutaneous) could be of worth in the best-option treatment, given their feasibility and good results when properly chosen.

Author Contributions: Conceptualization, M.G. and M.A.; methodology, M.G.; software, M.R. (Marta Rigoni); validation, M.A., G.P. and M.P.; formal analysis, M.R. (Marta Rigoni), P.M.; investigation, M.G.; resources, M.G., M.A., A.L.B.; data curation, G.M., P.T., M.R. (Maurizio Roberto), F.F., G.T., L.F., M.M.; writing—original draft preparation, M.G.; writing—review and editing, M.G.; visualization, M.A.; supervision, M.A.; project administration, M.P.; funding acquisition, N/A. All authors have read and agreed to the published version of the manuscript.

Funding: This research received no external funding.

Institutional Review Board Statement: The study was conducted according to the guidelines of the Declaration of Helsinki, and approved by the Institutional Review Board (or Ethics Committee) of IRCCS Centro Cardiologico Monzino (protocol code CCM 1459 10.02.2021).

Informed Consent Statement: Informed consent was obtained from all subjects involved in the study.

Data Availability Statement: All the data concerning this work are available from the corresponding author upon reasonable request.

Conflicts of Interest: The authors declare no conflict of interest for this work.

\section{References}

1. Mack, M.J.; Leon, M.B.; Thourani, V.H.; Makkar, R.; Kodali, S.K.; Russo, M.; Kapadia, S.R.; Malaisrie, S.C.; Cohen, D.J.; Pibarot, P. Transcatheter Aortic-Valve Replacement with a Balloon-Expandable Valve in Low-Risk Patients. N. Engl. J. Med. 2019, 380, 1695-1705. [CrossRef] [PubMed]

2. Popma, J.J.; Deeb, G.M.; Yakubov, S.J.; Mumtaz, M.; Gada, H.; O’Hair, D.; Bajwa, T.; Heiser, J.C.; Merhi, W.; Kleiman, N.S.; et al. Transcatheter Aortic-Valve Replacement with a Self-Expanding Valve in Low-Risk Patients. N. Engl. J. Med. 2019, 380, $1706-1715$. [CrossRef] [PubMed]

3. Ates, I.; Cilingiroglu, M. Percutaneous access versus surgical cut down for TAVR: Where do we go from here? Catheter Cardiovasc. Interv. 2018, 91, 1363-1364. [CrossRef] [PubMed]

4. Généreux, P.; Webb, J.G.; Svensson, L.G.; Kodali, S.K.; Satler, L.F.; Fearon, W.F.; Davidson, C.J.; Eisenhauer, A.C.; Makkar, R.R.; Bergman, G.W.; et al. Vascular complications after transcatheter aortic valve replacement: Insights from the PARTNER (Placement of AoRTic TraNscathetER Valve) trial. J. Am. Coll. Cardiol. 2012, 60, 1043-1052. [CrossRef] [PubMed]

5. Ando, T.; Briasoulis, A.; Holmes, A.A.; Takagi, H.; Slovut, D.P. Percutaneous versus surgical cut-down access in transfemoral transcatheter aortic valve replacement: A meta-analysis. J. Card. Surg. 2016, 31, 710-717. [CrossRef] [PubMed]

6. Drafts, B.C.; Choi, C.H.; Sangal, K.; Cammarata, M.W.; Applegate, R.J.; Gandhi, S.K.; Kincaid, E.H.; Kon, N.; Zhao, D.X. Comparison of outcomes with surgical cut-down versus percutaneous transfemoral transcatheter aortic valve replacement: TAVR transfemoral access comparisons between surgical cut-down and percutaneous approach. Catheter Cardiovasc. Interv. 2018, 91, 1354-1362. [CrossRef] [PubMed] 
7. Hayashida, K.; Lefèvre, T.; Chevalier, B.; Hovasse, T.; Romano, M.; Garot, P.; Mylotte, D.; Uribe, J.; Farge, A.; Donzeau-Gouge, P.; et al. Transfemoral aortic valve implantation new criteria to predict vascular complications. JACC Cardiovasc. Interv. 2011, 4, 851-858. [CrossRef] [PubMed]

8. Baumgartner, H.; Falk, V.; Bax, J.J.; De Bonis, M.; Hamm, C.; Holm, P.J.; Lung, B.; Lancellotti, P.; Lanac, E.; Muñoz, D.R.; et al. 2017 ESC/EACTS Guidelines for the management of valvular heart disease. Eur. Heart J. 2017, 38, 2739-2791. [CrossRef] [PubMed]

9. Kappetein, A.P.; Head, S.J.; Généreux, P.; Piazza, N.; van Mieghem, N.M.; Blackstone, E.H.; Brott, T.G.; Cohen, D.J.; Cutlip, D.E.; van Es, G.A.; et al. Valve Academic Research Consortium (VARC)-2. Updated standardized endpoint definitions for transcatheter aortic valve implantation: The Valve Academic Research Consortium-2 consensus document (VARC-2). Eur. J. Cardiothorac. Surg. 2012, 42, 45-60. [CrossRef] [PubMed]

10. Van Mieghem, N.M.; Nuis, R.J.; Piazza, N.; Apostolos, T.; Ligthart, J.; Schultz, C.; de Jaegere, P.P.; Serruys, P.W. Vascular complications with transcatheter aortic valve implantation using the 18 Fr Medtronic CoreValve System: The Rotterdam experience. EuroIntervention 2010, 5, 673-679. [CrossRef] [PubMed]

11. Ducrocq, G.; Francis, F.; Serfaty, J.M.; Himbert, D.; Maury, J.M.; Pasi, N.; Marouene, S.; Provenchère, S.; Iung, B.; Castier, Y.; et al. Vascular complications of transfemoral aortic valve implantation with the Edwards SAPIEN prosthesis: Incidence and impact on outcome. EuroIntervention 2010, 5, 666-672. [CrossRef] [PubMed]

12. Toggweiler, S.; Gurvitch, R.; Leipsic, J.; Wood, D.A.; Willson, A.B.; Binder, R.K.; Cheung, A.; Ye, J.; Webb, J.G. Percutaneous aortic valve replacement: Vascular outcomes with a fully percutaneous procedure. J. Am. Coll. Cardiol. 2012, 59, 113-118. [CrossRef] [PubMed]

13. Okuyama, K.; Jilaihawi, H.; Kashif, M.; Takahashi, N.; Chakravarty, T.; Pokhrel, H.; Patel, J.; Forrester, J.S.; Nakamura, M.; Cheng, W.; et al. Transfemoral access assessment for transcatheter aortic valve replacement: Evidence-based application of computed tomography over invasive angiography. Circ. Cardiovasc. Imaging 2014, 8, e01995. [CrossRef] [PubMed]

14. Vincent, F.; Spillemaeker, H.; Kyheng, M.; Belin-Vincent, C.; Delhaye, C.; Piérache, A.; Denimal, T.; Verdier, B.; Debry, N.; Moussa, M. Ultrasound Guidance to Reduce Vascular and Bleeding Complications of Percutaneous Transfemoral Transcatheter Aortic Valve Replacement: A Propensity Score-Matched Comparison. J. Am. Heart Assoc. 2020, 9, e014916. [CrossRef] [PubMed]

15. Yanagawa, B.; Graham, M.M.; Afilalo, J.; Hassan, A.; Arora, R.C. Frailty as a risk predictor in cardiac surgery: Beyond the eyeball test. J. Thorac. Cardiovasc. Surg. 2019, 157, 1905-1909. [CrossRef] [PubMed]

16. Baekke, P.S.; Jørgensen, T.H.; Søndergaard, L. Impact of early hospital discharge on clinical outcomes after transcatheter aortic valve implantation. Catheter Cardiovasc. Interv. 2020. [CrossRef] [PubMed]

17. Torsello, G.B.; Kasprzak, B.; Klenk, E.; Tessarek, J.; Osada, N.; Torsello, G.F. Endovascular suture versus cutdown for endovascular aneurysm repair: A prospective randomized pilot study. J. Vasc. Surg. 2003, 38, 78-82. [CrossRef]

18. Goldsweig, A.M.; Tak, H.J.; Chen, L.W.; Aronow, H.D.; Shah, B.; Kolte, D.; Desai, N.R.; Szerlip, M.; Velagapudi, P.; Abbott, J.D. Relative Costs of Surgical and Transcatheter Aortic Valve Replacement and Medical Therapy. Circ. Cardiovasc. Interv. 2020, 13, e008681. [CrossRef] [PubMed]

19. Nakamura, M.; Chakravarty, T.; Jilaihawi, H.; Doctor, N.; Dohad, S.; Fontana, G.; Cheng, W.; Makkar, R.R. Complete percutaneous approach for arterial access in transfemoral transcatheter aortic valve replacement: A comparison with surgical cut-down and closure. Catheter Cardiovasc. Interv. 2014, 84, 293-300. [CrossRef] [PubMed]

20. Holper, E.M.; Kim, R.J.; Mack, M.; Brown, D.; Brinkman, W.; Herbert, M.; Stewart, W.; Vance, K.; Bowers, B.; Dewey, T. Randomized trial of surgical cutdown versus percutaneous access in transfemoral TAVR. Catheter Cardiovasc. Interv. 2014, 83, 457-464. [CrossRef] [PubMed] 